\title{
Polymerization shrinkage, shrinkage stress, and mechanical evaluation of novel prototype dental composite resin
}

\author{
$\mathrm{Na} \mathrm{ZHANG}^{1}$ and Chao XIE ${ }^{2}$ \\ ${ }^{1}$ Department of Endodontics, School of Stomatology, Wannan Medical College, 22 West Weng-chang Road, Wuhu, Anhui 241001, China \\ ${ }^{2}$ Department of Oral Implantology, School of Stomatology, Fourth Military Medical University, 145 West Chang-le Road, Xi'an, Shannxi 710032, \\ China \\ Corresponding author, Chao XIE; E-mail: XIECHAO20062012@outlook.com
}

\begin{abstract}
A new photocurable composite resin for dental restorations was synthesized using a monovinyl acrylate diluent. Its polymerization shrinkage, shrinkage stress, degree of conversion, and mechanical properties were investigated and compared to those of a conventional composite resin synthesized using a triethyleneglycol dimethacrylate diluent as well as three commercial resins: Tetric N-Ceram, Neofil, and Gradia Direct. The polymerization shrinkage and shrinkage stress of the new composite resin were statistically lower than those of the conventional resin $(p<0.05)$, but not those of the commercial resins $(p>0.05)$. The degree of conversion of the new resin was statistically better than all other tested resins $(p<0.05)$ except the Neofil resin $(p>0.05)$. The mechanical properties of the resins were not statistically different $(p>0.05)$. Overall, the new composite resin exhibited less polymerization shrinkage, lower shrinkage stress, a higher degree of conversion, and similar mechanical properties to the other resins, demonstrating its potential for clinical application.
\end{abstract}

Keywords: Resin monomer, Polymerization shrinkage, Polymerization shrinkage stress, Degree of conversion, Mechanical properties

\section{INTRODUCTION}

Composite resin restoration has become an important field in clinical dental restoration. Composite resins have extensive applicability in clinical dentistry ${ }^{1)}$ owing to their ease of operation ${ }^{2)}$, beneficial physiochemical properties, wide range of color and lustre options, and strong biocompatibility. However, resin monomers undergo polymerization shrinkage (PS) in the range of $1.67-5.68 \%^{3)}$ when exposed to light, transforming them into reticular structures. In composite resins, PS causes shrinkage stress, resulting in cuspal cracking, enamel fracture, and postoperative pain ${ }^{4}$. PS may also result in marginal discoloration, marginal gaps, and micro-leakages ${ }^{5}$. Marginal gaps between a tooth and a restoration, are a major cause of dental caries ${ }^{6}$. Thus, reducing the volumetric shrinkage of composite resins remains an important research topic.

Significant research has been conducted on reducing PS in composite resins, with particular emphasis on developing low-shrinkage composite resins ${ }^{7-10)}$. One phenomenon that has been extensively investigated is 'ring-opening polymerization', which occurs when a spiroorthocarbonate is exposed to a certain catalyst, causing volumetric expansion of the resulting polymer ${ }^{11,12)}$. However, the resulting materials exhibit poor mechanical properties, and the ring-opening reaction produces undesirable residues ${ }^{13,14)}$. Ge et al. found that using high-molecular-weight dimethacrylate monomers, such as 2,2-bis\{4-[2-methacryloxy-3-(4'tert-butylphenoxy)prop-1-oxy]phenyl\}propane and 2,2-

Color figures can be viewed in the online issue, which is available at J-STAGE.

Received Aug 29, 2019: Accepted Dec 29, 2019

doi:10.4012/dmj.2019-286 JOI JST.JSTAGE/dmj/2019-286 bis $\left\{4\right.$-[2-methacryloxy-3-( $3^{\prime}, 5^{\prime}$-di-tert-butylphenoxy) prop-1-oxy]phenyl\}propane, can reduce the PS of the resulting composite resin ${ }^{15}$. In addition, researchers have attempted to reduce the PS of composite resins using bisphenol A-glycidyl methacrylate (Bis-GMA) derivatives, but the use of these monomers did not reduce the PS to the desired level. Low-viscosity BisGMA replacements have been studied, and although the PS was reduced to a certain degree, problems relating to inferior mechanical properties and water absorption were not resolved ${ }^{16-18)}$.

To address the above issues, we propose that resin monomers that are screened from a series of monovinyl acrylate resin monomers with secondary functional groups could be used to form suitable photocurable composite resins. These resin monomers can undergo polymerization with common resin monomers for dental applications; moreover, they exhibit a high reactivity, conversion ratio, and storage stability, and can effectively reduce the problems of PS and shrinkage stress associated with composite resins used in dental applications. In a pilot study, monovinyl acrylate resin monomers with secondary functional groups were synthesized. These resin monomers exhibited higher monomer conversion ratios than traditional resin monomers, as well as substantially lower degrees of oxygen inhibition during polymerization, as revealed by the thickness of the anaerobic layer on the resulting resin surfaces following light exposure.

In this experiment, a new monovinyl acrylate resin monomer, 2-(phenyl amino formaldehyde-based oxygen ethyl methacrylate) (BOCNA, Fig. 1(b)), was used to replace the conventional triethyleneglycol 
dimethacrylate (TEGDMA, Fig. 1(a)) diluent to synthesize a new photocurable composite resin. The physiochemical properties of the new composite resin were subsequently tested and compared with the conventional TEGDMA-based resin and three commercial composite resins. The null hypothesis was that the proposed photopolymerisable composite resin formulated with BOCNA monomer would exhibit similar properties to the conventional composite resin formulated with TEGDMA monomer.

\section{MATERIALS AND METHODS}

Materials selection and formulation of experimental composites

Three commercial photocurable composite resins (Tetric<smiles>C=C(C)C(=O)OCCOCCOCCOC(=O)C(=C)C</smiles>

(a) TEGDMA

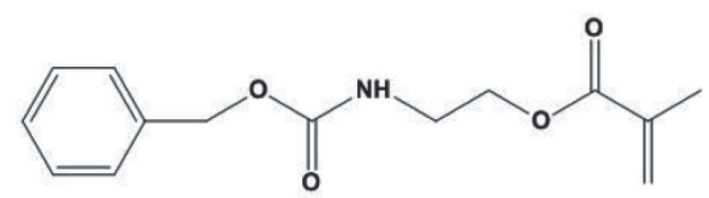

(b) BOCNA

Fig. 1 Chemical structures of (a) TEGDMA and (b) BOCNA.
N-Ceram, TN; Neofil, NE; and Gradia Direct, GD) and two experimental photocurable composite resins with similar filler levels and different diluent monomers were tested (see Table 1). The experimental composites comprised a Bis-GMA:TEGDMA (Esstech, Linwood, PA, USA) or Bis-GMA:BOCNA matrix, barium borosilicate glass filler (Esstech), and a photoinitiator comprising $0.5 \%$ camphoroquinone (CQ) $\left(\mathrm{C}_{10} \mathrm{H}_{4} \mathrm{O}_{2}, 97 \%\right.$, Sigma, San Francisco, CA, USA) and $0.5 \%$ dimethylaminoethyl methacrylate (DMAEMA) (98\%, Sigma). The BOCNA monomer was synthesized in the laboratory at Northwest Polytechnical University ${ }^{19)}$.

\section{Preparation of composite resins}

The composite resin specimens for the proposed composite group (BB) and Control Group 1 (BT) were prepared as follows: the principal resin monomer BisGMA was mixed with the diluent (BOCNA or TEGDMA, respectively) at a ratio of $7: 3(\mathrm{w} / \mathrm{w})$ and stirred in a magnetic stirrer for $30 \mathrm{~min}$. The photoinitiator (0.5\% CQ and $0.5 \%$ DMAEMA) was then added into the mixture, and the resulting mixture was stirred for $2 \mathrm{~h}$. Finally, the inorganic filler ( $75 \mathrm{wt} \%$ ) was added to the mixture, followed by vacuum stirring for $2 \mathrm{~h}$. The final mixture was stored in an environment without light exposure. Tetric N-Ceram (TN), Neofil (NE), and Gradia Direct (GD) were used for Control Groups 2 to 4, respectively (see Table 1).

Flexural strength and elastic modulus measurements Eight specimens measuring $25 \times 2 \times 2 \mathrm{~mm}$ were prepared using each resin, and subsequently used for flexural strength and elastic modulus measurements according to ISO standard $4049^{20)}$. the specimens were prepared and tested as follows: The photocurable resin was poured

Table 1 Composite materials used and their compositions ${ }^{\mathrm{a}}$

\begin{tabular}{|c|c|c|c|c|c|}
\hline Product & Code & $\begin{array}{l}\text { Filler } \\
\text { (wt\%) }\end{array}$ & Filler & Base resin & Manufacturer \\
\hline $\begin{array}{l}\text { Proposed } \\
\text { group }\end{array}$ & $\mathrm{BB}$ & 75 & $\begin{array}{l}\text { Barium borosilicate glass } \\
(0.7-2.0 \mu \mathrm{m})\end{array}$ & Bis-GMA $^{b}$, BOCNA $^{c}$ & - \\
\hline $\begin{array}{l}\text { Control } \\
\text { group } 1\end{array}$ & $\mathrm{BT}$ & 75 & $\begin{array}{l}\text { Barium borosilicate glass } \\
\text { ( } 0.7 \text { to } 2.0 \mathrm{um} \text { ) }\end{array}$ & Bis-GMA $^{\text {b }}$ TEGDMA ${ }^{d}$ & - \\
\hline $\begin{array}{l}\text { Tetric } \\
\text { N-Ceram }\end{array}$ & $\mathrm{TN}$ & $80-81$ & $\begin{array}{l}\text { Barium glass filler, Ytterbium } \\
\text { trifluoride, Mixed oxide } \\
(0.04-3.0 \mathrm{~nm})\end{array}$ & Bis-GMA $^{\mathrm{b}}, \mathrm{Bsis}^{-\mathrm{EMA}^{\mathrm{e}}}$ & $\begin{array}{l}\text { Ivoclar Vivadent } \\
\text { (Shaan, Liechtenstein) }\end{array}$ \\
\hline Neofil & $\mathrm{NE}$ & 75 & $\begin{array}{l}\text { Silica zirconium } \\
(0.02-0.7 \mathrm{~nm})\end{array}$ & $\begin{array}{l}\text { Bis-GMA }{ }^{\text {b }} \text { modified by } \\
\text { polycarbonate }\end{array}$ & $\begin{array}{l}\text { Kerr } \\
\text { (Orange, CA, USA) }\end{array}$ \\
\hline $\begin{array}{l}\text { Gradia } \\
\text { Direct }\end{array}$ & GD & 77 & $\begin{array}{l}\text { Silica, prepolymerised filler, } \\
\text { fluoroalumino-silicate glass } \\
(0.85 \mu \mathrm{m})\end{array}$ & $\begin{array}{l}\text { Hydroxyl ethyl methacrylate, } \\
\text { toluene trimethylcycloethyl } \\
\text { carbonate }\end{array}$ & $\begin{array}{l}\text { GC Dental Products } \\
\text { (Tokyo, Japan) }\end{array}$ \\
\hline
\end{tabular}

${ }^{a}$ Composition of base resin and filler content obtained from manufacturer's information, ${ }^{b}$ Bis-GMA: bisphenol A-glycidyl methacrylate, ${ }^{\mathrm{c}}$ BOCNA: 2-(phenyl amino formaldehyde-based oxygen ethyl methacrylate), ${ }^{\mathrm{d}}$ TEGDMA: triethyleneglycol

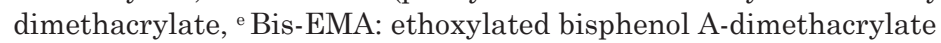


into a mold, and the specimen surface was covered with a thin polyethylene film. The specimen was then exposed to light from a light-emitting diode curing lamp (3M ESPE, St. Paul, MN, USA; wavelength: 430-480 $\mathrm{nm}$; light intensity: $600-800 \mathrm{~mW} / \mathrm{cm}^{2}$ ) for $60 \mathrm{~s}$ for every exposed area, then removed from the mold. The specimens were polished as follows: in the presence of injected water, the specimen was manually polished by successively applying 400-, 600-, 800-, 1000-, 1500-, 2000-, and 3000-grit sandpaper. Immediately after the polishing process, the specimen was subjected to ultrasonic cleaning. These operations were all performed by the same person. The specimen was then immersed in a temperature-controlled water bath at $37^{\circ} \mathrm{C}$ for $24 \mathrm{~h}$, and its width $w(\mathrm{~mm})$ and height $h(\mathrm{~mm})$ were measured and recorded. The deflection $d(\mathrm{~mm})$ was measured upon applying load $F(\mathrm{~N})$ in the elastic regime. The samples were tested on a universal testing machine at a loading speed of $0.5 \mathrm{~mm} / \mathrm{min}$, and the load $F(\mathrm{~N})$ was recorded. The flexural strength $\sigma_{\text {flex }}(\mathrm{MPa})$ and elastic modulus $E(\mathrm{GPa})$ were computed using the following equations ( $\operatorname{span} L=20 \mathrm{~mm}$ ):

$$
\sigma_{\text {flex }}=3 F L / 2 w h^{2} \text {. }
$$

$$
E=F L^{3} / 4 w h^{3} d
$$

\section{Compressive strength measurement}

Eight specimens measuring $4 \times 6 \mathrm{~mm}$ were prepared from each resin using the same molding process as for the flexural strength measurements, and subsequently used for compressive strength measurements according to ISO standard 4049. The specimens were polished using the procedure described above. The radii $r(\mathrm{~mm})$ of the specimens were measured and recorded after immersion in a temperature-controlled water bath. The samples were tested on a universal testing machine at a loading speed of $0.5 \mathrm{~mm} / \mathrm{min}$, and the failure load $F(\mathrm{~N})$ was recorded. The compressive strength $\sigma_{\text {com }}(\mathrm{MPa})$ was then computed using the following equation:

$$
\sigma_{\mathrm{com}}=F / \pi r^{2} \text {. }
$$

\section{Diametric tensile strength measurement}

Eight specimens measuring $3 \times 6 \mathrm{~mm}$ were prepared from each resin using the same molding process as for the flexural strength measurements, and subsequently used for diametric tensile strength measurements according to ISO standard 4049. The specimens were polished using the procedure described above. The diameters $d(\mathrm{~mm})$ and heights $h(\mathrm{~mm})$ of the specimens were measured and recorded after immersion in a temperature-controlled water bath. The specimens were tested on a universal testing machine at a loading speed of $0.5 \mathrm{~mm} / \mathrm{min}$, and the failure load $F(\mathrm{~N})$ was recorded. The diametric tensile strength $\sigma_{\text {DTS }}(\mathrm{MPa})$ was then computed using the following equation:

$$
\sigma_{\mathrm{DTS}}=2 F / \pi d h \text {. }
$$

\section{Microhardness measurement}

Eight specimens measuring $3 \times 6 \mathrm{~mm}$ were prepared from each resin using the same molding process as for the flexural strength measurements. After molding, the molded specimens were ground and polished, then immersed in a water bath at $37^{\circ} \mathrm{C}$ for $24 \mathrm{~h}$. Their Vickers hardness $\left(H_{\mathrm{v}}\right)$ values were then tested using a microhardness tester under a load of $100 \mathrm{~g}$, which was maintained for $15 \mathrm{~s}$.

\section{Degree of conversion (DC)}

The DC refers to the proportion of methacrylate double bonds in the organic resin matrix that are converted to single bonds. To measure the DC in this study, the number of double bonds in each resin before and after light curing was determined using Fourier-transform infrared (FTIR) spectroscopy (Shimadzu 8100M, Kyoto, Japan). First, potassium bromide (KBr) was pressed into a thin disk using a press and scanned as a background. The KBr disk was then coated with a trace amount of an uncured resin specimen. The infrared (IR) spectrum of the uncured resin specimen was subsequently recorded using the FTIR spectrometer. Afterwards, the uncured resin-coated $\mathrm{KBr}$ disk was removed from the spectrometer and subjected to light curing for $20 \mathrm{~s}$. The KBr disk was then placed back into the FTIR spectrometer to record IR spectra at various time points (20, 40, 60, 120, 300, and $600 \mathrm{~s})$. The resolution and scanning range of the IR spectra were $4 \mathrm{~cm}^{-1}$ and 4,000-400 $\mathrm{cm}^{-1}$, respectively. Five repeated tests were conducted on each specimen. The DC was measured using the double bonds on the aromatic ring (peak position: $1,607 \mathrm{~cm}^{-1}$ ) as an internal standard, as these bonds did not participate in the polymerization reaction, and using the change in the peak area of the aliphatic double bonds (peak position: $\left.1,637 \mathrm{~cm}^{-1}\right)$, which participated in the reaction as a measurement index. The DC (\%) of the double bonds was calculated using the following equation:

$$
\mathrm{DC}=\left[1-\frac{\left(1637 \mathrm{~cm}^{-1} / 1607 \mathrm{~cm}^{-1}\right) \times \text { peak area cured }}{\left(1637 \mathrm{~cm}^{-1} / 1607 \mathrm{~cm}^{-1}\right) \times \text { peak area uncured }}\right] \times 100
$$

\section{PS measurement}

The PS was measured as follows: the uncured resin was placed in a cylindrical organic glass container (diameter, $6 \mathrm{~mm}$; height, $2 \mathrm{~mm}$ ) and then placed in the chamber of a micro-computed tomography (micro-CT) scanner (SIEMENS Inveon, Munich, Germany). The specimen was scanned using the following parametric settings: current, $500 \mu \mathrm{A}$; voltage, $80 \mathrm{kVp}$; layer thickness, 15 $\mu \mathrm{m}$; and light exposure time, $800 \mathrm{~ms}$. Subsequently, the scanned specimen was exposed to light for $60 \mathrm{~s}$ by placing a light-curing lamp $1 \mathrm{~mm}$ vertically above the specimen. The specimen was allowed to fully cure and then rest for $1 \mathrm{~h}$, after which it was placed back in the micro-CT scanning chamber. The obtained three-dimensional (3D) digital images were imported into Inveon software for 3D reconstruction. The measurement process was repeated on eight specimens of each resin (Table 2). The PS (\%) was computed using the following equation: 


$$
\mathrm{PS}=\left(V_{0}-V_{1}\right) / V_{0} \times 100 \% \text {, }
$$

where $V_{0}$ is the volume before curing, and $V_{1}$ is the volume after curing.

\section{PS stress measurement}

The PS stress $\sigma_{\mathrm{PS}}(\mathrm{MPa})$ was tested using a universal testing machine with a custom-made mold, as illustrated in Fig. $2^{5)}$. A support was manufactured using organic glass, and the top flat surface was coarsened by sand blasting. The support was then fixed onto the universal testing machine. A cylindrical stainless-steel mold (diameter, $6 \mathrm{~mm}$; height, $20 \mathrm{~mm}$ ) was manufactured and placed atop the glass support. One end of the mold was connected to a sensor, with the other end perpendicular to the glass support surface. The specimen was placed between the glass support and stainless-steel mold. The specimen height was controlled at $2 \mathrm{~mm}$ by lowering the mold and removing surplus resin. The specimen was then exposed to light for $300 \mathrm{~s}$. The measurement process was repeated on eight specimens of each resin (Table 2).

\section{Statistical analysis}

Statistical analysis of the obtained data was performed using the SPSS software (SPSS version 23, IBM, Armonk, NY, USA). The statistical differences between the proposed, conventional, and commercial resins were analyzed using one-way ANOVA and Tukey's post hoc comparison test, with $p<0.05$ indicating statistical significance.

\section{RESULTS}

The $\sigma_{\text {flex }}, E, \sigma_{\text {com }}, \sigma_{\text {DTS }}$, and $H_{\mathrm{v}}$ values for the five composite resins are listed in Table 3 . The $E$ of TN was higher than those of $\mathrm{BB}, \mathrm{TN}, \mathrm{NE}$, and GD. The results demonstrate that BB, BT, NE, and GD all exhibited comparable $E$ values $(p>0.05)$. In addition, $\mathrm{BB}$ and $\mathrm{BT}$ exhibited comparable $\sigma_{\text {flex }}, \sigma_{\text {com }}, \sigma_{\text {DTS }}$, and $H_{\mathrm{v}}(p>0.05)$ values.

Table 2 summarizes the DC values for the five composite resin groups. As demonstrated in Table 2, the

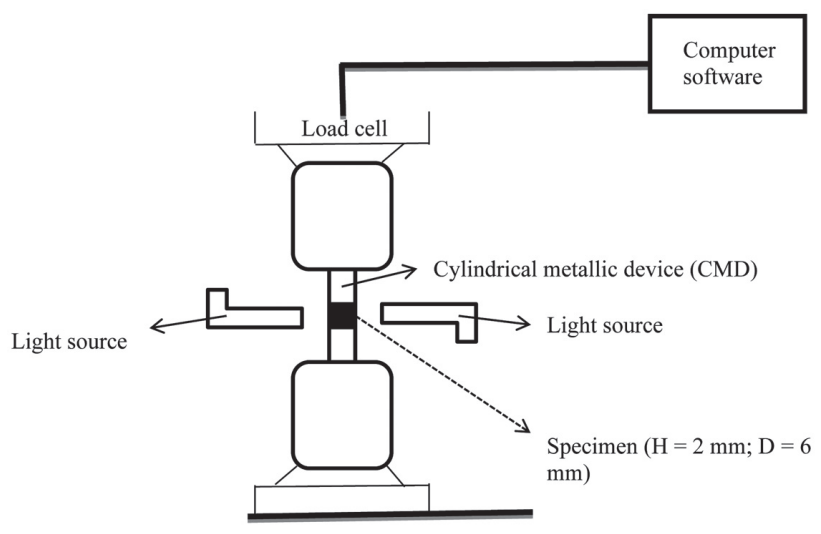

Fig. 2 Setup for PS stress measurement.

Table 2 Degree of conversion (DC), polymerization shrinkage (PS), and polymerization shrinkage stress $\left(\sigma_{\mathrm{PS}}\right)$ of the composite resins listed in Table 1

\begin{tabular}{cccc}
\hline Materials & DC & PS & $\sigma_{\text {PS }}($ diameter: 6 mm $)$ \\
\hline BB & $81.21(1.09)^{\mathrm{a}}$ & $1.88(0.17)^{\mathrm{a}}$ & $2.67(0.26)^{\mathrm{a}}$ \\
BT & $74.84(0.88)^{\mathrm{b}}$ & $3.29(0.26)^{\mathrm{b}}$ & $3.88(0.17)^{\mathrm{b}}$ \\
TN & $78.99(0.74)^{\mathrm{b}}$ & $1.93(0.16)^{\mathrm{a}}$ & $2.59(0.34)^{\mathrm{a}}$ \\
NE & $79.81(1.02)^{\mathrm{a}}$ & $2.01(0.24)^{\mathrm{a}}$ & $2.65(0.36)^{\mathrm{a}}$ \\
GD & $76.98(0.79)^{\mathrm{b}}$ & $2.09(0.57)^{\mathrm{a}}$ & $3.02(0.15)^{\mathrm{a}}$ \\
\hline
\end{tabular}

a,b These groups were statistically different $(p<0.05)$.

Table 3 Flexural strength $\left(\sigma_{\mathrm{flex}}\right)$, elastic modulus $(E)$, compressive strength $\left(\sigma_{\mathrm{com}}\right)$, diametric tensile strength $\left(\sigma_{\mathrm{DTS}}\right)$, and Vickers hardness $\left(H_{\mathrm{v}}\right)$ of the composite resins listed in Table 1

\begin{tabular}{cccccc}
\hline Material & $\Sigma_{\text {flex }}(\mathrm{MPa})$ & $E(\mathrm{GPa})$ & $\sigma_{\text {com }}(\mathrm{MPa})$ & $\sigma_{\text {DTS }}(\mathrm{MPa})$ & $H_{\mathrm{v}}(\mathrm{MPa})$ \\
\hline BB & $107.27(6.37)^{\mathrm{a}}$ & $7.28(0.08)^{\mathrm{a}}$ & $321.58(3.88)^{\mathrm{a}}$ & $29.85(1.21)^{\mathrm{a}}$ & $65.95(2.97)^{\mathrm{a}}$ \\
BT & $112.98(5.92)^{\mathrm{a}}$ & $7.31(0.06)^{\mathrm{a}}$ & $324.39(6.46)^{\mathrm{a}}$ & $32.69(3.12)^{\mathrm{a}}$ & $66.28(1.25)^{\mathrm{a}}$ \\
TN & $114.46(4.04)^{\mathrm{a}}$ & $7.61(0.04)^{\mathrm{b}}$ & $329.10(4.33)^{\mathrm{a}}$ & $31.49(2.35)^{\mathrm{a}}$ & $68.14(1.50)^{\mathrm{a}}$ \\
NE & $110.63(4.57)^{\mathrm{a}}$ & $7.26(0.10)^{\mathrm{a}}$ & $326.65(8.66)^{\mathrm{a}}$ & $32.27(1.57)^{\mathrm{a}}$ & $65.75(2.34)^{\mathrm{a}}$ \\
GD & $112.08(5.37)^{\mathrm{a}}$ & $7.33(0.06)^{\mathrm{a}}$ & $327.85(5.72)^{\mathrm{a}}$ & $30.19(1.53)^{\mathrm{a}}$ & $67.74(2.16)^{\mathrm{a}}$ \\
\hline
\end{tabular}

a These groups were statistically similar ( $p>0.05)$. a,b These groups were statistically different $(p<0.05)$. 


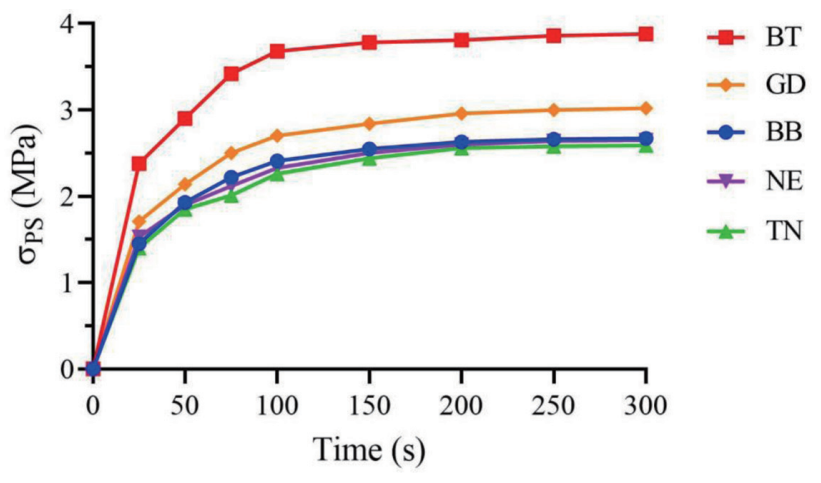

Fig. 3 PS stress $\sigma_{\mathrm{PS}} v s$. time at room temperature.

$\mathrm{DC}$ of $\mathrm{BB}$ was statistically different from those of $\mathrm{BT}$, TN, and GD $(p<0.05)$, but not statistically different from that of NE $(p>0.05)$.

The PS results are presented in Table 2 . It can be observed that $\mathrm{BB}$ exhibited the lowest PS $(p<0.05)$ out of all the composite resins, whereas BT had the highest PS $(p<0.05)$ among all the composite resins. The PS of BB was statistically similar to those of TN, NE, and GC $(p>0.05)$.

Table 2 displays the $\sigma_{\mathrm{PS}}$ values, while Fig. 3 illustrates $\sigma_{\mathrm{PS}} v s$. time $t$. The $\sigma_{\mathrm{PS}}$ of $\mathrm{BB}$ was the same as those of TN, NE, and GD $(p>0.05)$, but lower than that of BT. TN, NE, and GD exhibited comparable $\sigma_{\mathrm{PS}}$ values (Table 2). $\sigma_{\mathrm{PS}}$ developed rapidly after light curing began, and then continued to increase at a reduced rate up to the fixed measuring time for all groups.

\section{DISCUSSION}

We evaluated the prospect of using a new resin (BB; formed with BOCNA diluent) in clinical applications by comparing it a conventional composite resin (BT; formed with TEGDMA diluent) and to three common commercial resins (TN, NE, and GD). Based on our findings, the null hypothesis that the $\mathrm{BB}$ and $\mathrm{BT}$ composite resins would perform equally well was rejected. While BB and BT had comparable mechanical properties, BB exhibited reduced PS and a lower $\sigma_{\mathrm{PS}}$. Compared to the three commercial resins, BB exhibited a lower PS and superior mechanical properties.

The mechanical properties of composite resins are affected by the properties of the filler ${ }^{21}$ and the resin matrix structure ${ }^{22}$. Once in place, dental restorations are liable to fracture under the stress caused by repetitive mastication, primarily owing to the development of microcracks in areas of the restorative material that develop under stress concentrations. The material is continually subjected to load in the mouth cavity, causing microcracks to merge into larger cracks, and finally leading to failure of the material. The force acting on a dental restoration or filler in the mouth cavity is not purely tensile or compressive ${ }^{23}$; it is a combination of forces acting on multiple points. $\sigma_{\text {flex }}$, which is the maximum stress withstood by a material before it fractures owing to bending stress, is a measure of the capability of the material to bear complex stresses ${ }^{24}$. In the context of this study, this is related to the performance of the resin matrix and filler. The elastic modulus $E$ is used to quantitatively characterize the capacity of a material to resist deformation when subjected to an external tensile or compressive force. Ideally, the $E$ of a restorative material should be as similar to that of the dental tissues as possible. A restorative material with an excessively high $E$ will result in significant hardness of the tooth neck, making it unable to bend to accommodate oral functions. By contrast, restorative materials with relatively high $E$ values are required for occlusal and proximal tooth surfaces to resist flexural cuspal deflection ${ }^{25}$. Therefore, $\sigma_{\text {flex }}$ and $E$ were measured using three-point bending tests.

The compressive strength $\sigma_{\text {com }}$ and diametric tensile strength $\sigma_{\text {DTS }}$ are important measures of the mechanical properties of a material, and can fully reflect the mastication biting force. A restoration with a higher $\sigma_{\mathrm{com}}$ value exhibits a superior capability to resist continuous mastication load ${ }^{26}$. Thus, $\sigma_{\text {com }}$ is an effective indicator of the mechanical behavior of restorative materials. The hardness $H_{\mathrm{v}}$ of a material is a measure of its degree of softness or hardness, and indicates its ductility and polishability. It is used to characterize the capability of the material to resist localized compressive deformation and fracture ${ }^{27}$. A material with poor surface hardness tends to exhibit poor mechanical properties, particularly wear resistance, and therefore a short service life. The experimental results contained in this study demonstrated that the $\sigma_{\text {flex }}, E, \sigma_{\text {com }}, \sigma_{\text {DTS }}$, and $H_{\mathrm{v}}$ values of group BB were 107.27 MPa, 7.28 GPa, 321.58 $\mathrm{MPa}, 29.85 \mathrm{MPa}$, and $65.95 \mathrm{MPa}$, respectively, thereby satisfying all the requirements of ISO standard 4049 and clinical applications ${ }^{22)}$. Moreover, these properties were not statistically different from those of NE and GD $(p>0.05)$.

The DC of double bonds is a primary index that reflects the degree of curing of a resin. It significantly affects the post-curing physical and mechanical properties, because the number of residual unreacted double bonds is closely related to the mechanical, physical, and chemical properties of the cured resin ${ }^{28)}$. The experimental results in this study demonstrated high DCs for both BB and BT. TEGDMA is a type of methacrylate; during the course of photopolymerization, the methyl group can stabilize the free radical induced by the double bond, thus decreasing the activity of chain propagation, and ultimately decreasing the reaction speed and conversion rate. However, BOCNA is a type of acrylate, which has no stabilising effect; thus, it presents a better reaction speed and conversion rate. The DC of BB was not statistically different to that of $\mathrm{NE}$, although it was statistically higher than those of $\mathrm{TN}$ and GD $(p<0.05)$.

Composite resins have been used extensively for anterior and posterior restorations ${ }^{29,30)}$. Despite the numerous advances that have been made in terms of 
techniques and materials ${ }^{31,32)}$, various problems remain, with the greatest being $\mathrm{PS}^{33)}$. PS is intrinsically related to the structure of the resin material used ${ }^{34)}$. Various methods have been used to measure PS in recent years, such as dilatometry, density measurements, video image processing, and displacement sensor measurements. However, these methods all exhibit limitations, including complex operation and inaccurate results. With the use of micro-CT, $3 \mathrm{D}$ digital images of micro-objects can be obtained non-destructively ${ }^{35)}$. The major working principle of tomography is that of $3 \mathrm{D}$ reconstruction; a composite resin with radio-opaque components is scanned, and its volume is reconstructed using a software package. Sun and Lin-Gibson ${ }^{36)}$ found that the resin volumes can be effectively measured before and after polymerization using micro-CT, allowing accurate determination of the magnitude of PS. This method exhibits obvious advantages over the density measurement method. For example, several specimens can be measured simultaneously, with no strict requirements for the specimen size and shape.

The PS ratios of the resins were obtained by scanning the specimens before and after polymerization using a micro-CT scanner and computing their volumes using a software package. The BB and BT resins were prepared using a silanized inorganic filler $(0.7-2.0 \mu \mathrm{m})$. With the filler uniformly distributed in the resin matrix, the resin volume can be measured accurately using micro$\mathrm{CT}$, owing to the radio-opaque property of the filler. The PS of the proposed composite group was smaller than those of the control groups (Table 2). The experimental results demonstrated that the PS values of BB (1.83\%) and BT $(3.29 \%)$ were statistically different $(p<0.05)$. The shrinkage stresses $\sigma_{\mathrm{PS}}$ of BB and BT were 2.67 and $3.88 \%$, respectively, and also statistically different.

The process of resin polymerization results in an increase in the density and a decrease in the volume of the resin ${ }^{37)}$. However, PS is affected by many factors, including the monomer structure, initiator activity, and filler content ${ }^{38)} \cdot \sigma_{\mathrm{PS}}$ is a dynamic phenomenon, and is influenced by the type of resin matrix used ${ }^{39)}$. In this study, the BB and BT resins were prepared with the same filler, initiator, and principal monomer, but different diluents (BOCNA and TEGDMA, respectively). BOCNA has only one functional group with a $\mathrm{C}=\mathrm{C}$ double bond, while the conventional diluent TEGDMA has an additional functional group. With one less $\mathrm{C}=\mathrm{C}$ double bond, BOCNA has a smaller intermolecular distance than TEGDMA (0.15 $\mathrm{nm}$ vs. $0.3-0.5 \mathrm{~nm})$, and the resulting polymer has a lower cross-linking density ${ }^{40)}$, therefore resulting in a decrease in volumetric shrinkage ${ }^{41)}$. Although the impact of the monomer content on the resin properties remains unclear, we can infer that BOCNA contributes to a lower reticular cross-linking structure content in the resulting polymer, thereby leading to a lower $\sigma_{\mathrm{PS}}$.

In this study, $\sigma_{\mathrm{PS}}$ was measured using a universal testing machine. It is important to note the shortcomings of existing methods for $\sigma_{\mathrm{PS}}$ measurement. The method employed in this study exhibited low compliance; consequently, the stress values tended to be higher than those recorded using compliant systems ${ }^{42}$. Further research is therefore required to evaluate these findings using a clinically relevant and compliant system. The specimen remained connected to the sensor during the entire $300 \mathrm{~s}$ of $\sigma_{\mathrm{PS}}$ measurement for all the resins. All tested resins yielded similar compressive stress versus time curves, which is consistent with the typical stress variation curves reported in the literature ${ }^{43)}$. The stress variation trend is related to the gelation effect caused by the rapid increase in polymer viscosity. As polymerization proceeds, the free flow of monomers in the reaction system is constrained, and the decreased monomer content towards the end of the process results in drastically decreasing stress ${ }^{44)}$. This stress variation represents the trend of the polymer system, which develops a reticular cross-linking structure ${ }^{45)}$.

The proposed resin synthesized using the new diluent exhibited strong mechanical properties, low $\mathrm{PS}$, a relatively high DC, and low $\sigma_{\mathrm{PS}}$. However, certain problems remain that should be experimentally investigated; for example, the water absorption and biological behaviors of the resulting resin.

\section{CONCLUSIONS}

The TEGDMA diluent used to synthesize a conventional photocurable composite resins for use in clinical dental restorations was replaced by a new BOCNA diluent. The properties of the proposed photocurable composite resin were compared to those of the conventional resin as well as three commercial resins (Tetric N-Ceram, Neofil, and Gradia Direct). The resin synthesized with BOCNA exhibited less shrinkage, lower shrinkage stress, and equally strong mechanical properties compared to the conventional resin. This is because the BOCNA monomer has only one functional group with a $\mathrm{C}=\mathrm{C}$ double bond, while the TEGDMA monomer has an additional functional group. The new BOCNA-based composite resin is promising for restorations that have low shrinkage to inhibit secondary caries. To improve the overall performance of the resin, its solubility, water absorption, and cytotoxicity, and as well as the impact of the filler content on performance will be investigated in the future.

\section{ACKNOWLEDGMENTS}

We thank the Esstech Company for providing the monomers used in this study. This study was supported by the Wannan Medical College through a Major Research Project Support Fund (WK2018Z02), and the School of Stomatology, Fourth Military Medical University.

\section{REFERENCES}

1) Sakguchi RL, Wiltbank BD, Murchison CF. Cure induced stresses and damage in particulate reinforced polymer matrix composites: a review of the scientific literature. Dent Mater 2005; 21: 43-46.

2) Demarco FF, Correa MB, Cenci MS, Moraes RR, Opdam 
NJ. Longevity of posterior composite restorations: not only a matter of materials. Dent Mater 2012; 28: 87-101.

3) Bausch JR, de Lange K, Davidson CL, Peters A, de Gee AJ. Clinical significance of polymerization shrinkage of composite resins. J Prosthet Dent 1982; 48: 59-67.

4) Taha NA, Palamara JE, Messer HH. Cuspal deflection, strain and microleakage of endodontically treated premolar teeth restored with direct resin composites. J Dent 2009; 37: 724730.

5) Giachetti L, Scaminaci Russo D, Bambi C, Grandini R. A review of polymerization shrinkage stress: current techniques for posterior direct resin restorations. J Contemp Dent Pract 2006; 7: 79-88.

6) Totiam P, Gonzalez-Cabezas C, Fontana MR, Zero DT. A new in vitro model to study the relationshio of gap size and secondary caries. Caries Res 2007; 41: 467-473.

7) Eick JD, Byerley TJ, Chappell RP, Chen GR, Bowles CQ, Chappelow CC. Properties of expanding SOC/epoxy copolymers for dental use in dental composites. Dent Mater 1993; 9: 123-127.

8) He J, Liao L, Liu F, Luo Y, Jia D. Synthesis and characterization of a new dimethacrylate monomer based on 5,5'-bis(4-hydroxylphenyl)-hexahydro-4,7-methanoindan for root canal sealer application. J Mater Sci Mater Med 2010; 21: 1135-1142.

9) Atai M, Ahmadi M, Babanzadeh S, Watts DC. Synthesis, characterization, shrinkage and curing kinetics of a new low-shrinkage urethane dimethacrylate monomer for dental applications. Dent Mater 2007; 23: 1030-1041.

10) Liu W, Chen S, Liu Y, Ma Y, Wang N, Zhang Z, et al. Synthesis of a liquid-crystalline resin monomer with the property of low shrinkage polymerization. Dent Mater J 2013; 32: 550-556.

11) Acosta Ortiz R, Reyna Medina LA, Berlanqa Duarte ML, Ibarra Samaniego L, Garcia Mendez ZL, Mendez Gonzalez L. Synthesis of glycerol-derived diallyl spiroorthocarbonates and the study of their antishrinking properties in acrylic dental resins. J Mater Sci Mater Med 2013; 24: 2077-2084.

12) $\mathrm{Fu} \mathrm{J,} \mathrm{Liu} \mathrm{W,} \mathrm{Hao} \mathrm{Z}, \mathrm{Wu} \mathrm{X}$, Yin J, Panjiyar A, et al. Characterization of a low shrinkage dental composite containing bismethylena spiroorthocarbonate expanding monomer. Int J Mol Sci 2014; 15: 2400-2412.

13) Moon EJ, Lee JY, Kim CK, Cho BH. Dental restorative composites containing 2,2-Bis-[4-(2-Hydroxy3-Methacryloyloxy Propoxy) Phenyl] propane derivatives and spiro orthocarbonates. J Biomed Mater Res B Appl Biomater 2005; 73: 338-346.

14) Stansbury JW. Synthesis and evaluation of new oxaspiro monomers for double ring-opening polymerization. J Dent Res 1992; 71: 1408-1412.

15) Ge J, Trujillo M, Stansbury J. Synthesis and photopolymerization of low shrinkage methacrylate monomers containing bulky substituent groups. Dent Mater 2005; 21: 1163-1169.

16) Kalachandra S, Sankarapandian M, Shobha HK, Taylor DF, McGrath JE. Influence of hydrogen bonding on properties of BIS-GMA analogues. J Mater Sci Mater Med 1997; 8: 283286.

17) Sankarapandian M, Shobha HK, Kalachandra S, McGrath JE, Taylor DF. Characterization of some aromatic dimethacrylates for dental composite applications. J Mater Sci Mater Med 1997; 8: 465-468.

18) Shobha HK, Sankarapandian M, Kalachandra S, McGrath JE, Taylor DF. Effect of dilution on the kinetics of crosslinking thermal polymerization of dental composite matrix resins. J Mater Sci Mater Med 1997; 8: 583-586.

19) Han Y, Xie C. Synthesis and characterization of an experimental light-curing dental resinous monomer. Adv Mater Res 2014; 893: 337-340.

20) ISO 4049: 2000. Dentistry-Polymer-based filling, restorative and luting materials.

21) Ling L, Xu X, Choi GY, Billodeaux D, Guo G, Diwan RM. Novel F-releasing composite with improved mechanical properties. J Dent Res 2009; 88: 83-88.

22) Kawaguchi M, Fukushima T, Horibe T. Effect of monomer structure on the mechanical properties of light-cured unfilled resins. Dent Mater J 1988; 7: 174-181.

23) Meenakumari C, Bhat M, Bansal R, Singh N. Evaluation of mechanical properties of newer nanoposterior restorative resin composites: An in vitro study. Contemp Clin Dent 2018; 9: $142-146$

24) Rodrigues Junior SA, Zanchi CH, Carvalho RV, Demarco FF. Flexural strength and modulus of elasticity of different types of resin-based composites. Braz Oral Res 2007; 21: 16-21.

25) Doğan OM, Bolayir G, Keskin S, Doğan A, Bek B. The evaluation of some flexural properties of a denture base resin reingorced with various aesthetic fibers. J Mater Sci Mater Med 2008; 19: 2343-2349.

26) Kaya MS, Bakkal M, Durmus A, Durmus Z. Structural and mechanical properties of a giomer-based bulk restorative in different curing conditions. J Appl Oral Sci 2018; 26: 662672.

27) Baudin C, Osorio R, Toledano M, de Aza S. Work of fracture of a composite resin: fracture-toughening mechanisms. J Biomed Mater Res A 2009; 89: 751-758.

28) Asmussen E. Factors affecting the quantity of remaining double bonds in restorative resin polymers. Scand J Dent Res 1982; 90: 490-496.

29) Pallesen U, van Dijken JW. A randomized controlled 30 years follow up of three conventional resin composites in classII restorations. Dent Mater 2015; 31: 1232-1244.

30) Heintze SD, Rousson V. Clinical effectiveness of direct class II restorations-a neta-analysis. J Adhes Dent 2012; 14: 407431.

31) Rosatto CM, Bicalho AA, Verissimo C, Braganca GF, Rodrigues MP, Tantbirojn D, et al. Mechanical properties, shrinkage stress, cuspal strain and fracture resistance of molars restored with bulk-fill composites and incremental filling technique. J Dent 2015; 43: 1519-1528.

32) van Dijken JW, Pallesen U. Posterior bulk-filled resin composite restorations: a 5-year randomized controlled clinical study. J Dent 2016; 51: 29-35.

33) Bicalho AA, Valdívia AD, Barreto BC, Tantbirojn D, Versluis A, Soares CJ. Incremental filling technique and composite material-part II: shrinkage and shrinkage stresses. Oper Dent 2014; 39: 83-92.

34) Moorthy A, Hogg CH, Dowling AH, Grufferty BF, Benetti AR, Fleming GJ. Cuspal deflection and microleakage in premolar teeth restored with bulk-fill flowable resin based composite base materials. J Dent 2012; 40: 500-505.

35) Zeiger DN, Sun J, Schumacher GE, Lin-Gibson S. Evaluation of dental composite shrinkage and leakage in extracted teeth using X-ray microcomputed tomography. Dent Mater 2009; 25: $1213-1220$.

36) Sun J, Lin-Gibson S. X-ray microcomputed tomography for measuring polymerization shrinkage of polymeric dental composites. Dent Mater 2008; 24: 228-234.

37) Podgorski M. Synthesis and characterization of novel dimethacrylates of different chain lengths as possible dental resins. Dent Mater 2010; 26: 188-194.

38) Rodriguez-Lozano FJ, Serrano-Belmonte I, Perez Calvo JC, Coronado-Parra MT, Aernabeu-Esclapez A, Moraleda JM. Effects of two low-shrinkage composites on dental stem cells(viability,cell damaged or apoptosis and mesenchymal markers expression). J Mater Sci Med 2013; 24: 979-988.

39) Park HY, Kloxin CJ, Fordney MF, Bowman CN. Stress relaxation of trithiocarbonate dimethacrylate based dental composites. Dent Mater 2012; 28: 888-893.

40) Fadaie P, Atai M, Imani M, Karkhaneh A, Ghasaban S. 
Cyanoacrylate-POSS nanocomposites:novel adhesives with improved properties for dental applications. Dent Mater 2013; 29: 61-69.

41) Seo JH, Nakaqawa S, Hirata K, Yui N. Synthesis of a resin monomer-soluble polyrotaxane crosslinker containing cleavable end groups. Beilstein J Orq Chem 2014; 10: 26232629 .

42) Schneider LF, Cavalcante LM, Silikas N. Shrinkage stresses generated during resin composite applicatins: a review. J Dent Biomech 2010; 2010: 1316-1330.

43) Moraes RR, Garcia JW, Barros MD, Lewis SH, Pfeifer CS,
Liu J, et al. Control of polymerization shrinkage and stress in nanogel-modified monomer and composite materials. Dent Mater 2011; 27: 509-519.

44) Yamasaki LC, De Vito Moraes AG, Barros M, Lewis S, Francci C, Stansbury JW, et al. Polymerization development of "lowshrink" resin composites: Reaction kinetics, polymerization stress and quality of network. Dent Mater 2013; 29: 169-179.

45) Braga RR, Ballester RY, Ferracane JL. Factors involved in the development of polymerization shrinkage stress in resincomposites: a systematic review. Dent Mater 2005; 21: 962970. 